Андрієнко О.В. Державний науково-дослідний інститут випробувань $i$ сертифікації озброєння та військової техніки

Гученко М.І., Зінченко В.П., Тупіков К.С., Кушпіль А.А. Науково-виробниче об'єднання "ABIA"

\title{
ОПТИКО-ЕЛЕКТРОННИЙ МЕТОД ВИЗНАЧЕННЯ ТРАНСПОРТНОЇ ЗАТРИМКИ В СИСТЕМІ КЕРУВАННЯ ТРЕНАЖЕРА
}

\begin{abstract}
Вказується на наявність проблеми вимірювання т.зв. транспортної затримки керувальних впливів при валідаційних випробуваннях льотних тренажерів за міжнародними стандартами. Аналізуються недоліки стандартного методу вимірювання транспортної затримки. Пропонується $і$ описується альтернативний метод.
\end{abstract}

Ключові слова: льотний тренажер, валідаційні випробування, транспортна затримка.

Постановка проблеми. В умовах активної модернізації та вдосконалення авіаційної техніки залишається актуальним питання зменшення кількості авіаційних подій. Дані статистики говорять про те, що майже 80\% авіаційних подій відбувається через помилки екіпажу. Причиною 35\% цих помилок є недостатня професійна підготовка пілотів. Особливу увагу звертає, що причиною 40\% помилок є недосвідченість екіпажу [1].

Актуальність дослідження. Вартість професійної підготовки екіпажів вертольотів на комплексних льотних тренажерах на порядок менша аніж на реальних вертольотах. Тому, на сьогодні, одним з основних напрямків підвищення безпеки польотів є покращання рівня підготовки льотних екіпажів шляхом широкого використання льотних тренажерів. Отже, наявна практична проблема якості професійної підготовки льотних екіпажів є достатньо актуальною.

Основна частина. Інформаційна модель тренажера повинна якомога менше відрізнятися від інформаційної моделі реального вертольота. Базовими складовими тренажера є системи імітації, що забезпечують вплив на органи чуття людини інформації, необхідної для створення реальної картини польоту. Так органи зору сприймають інформацію завдяки роботі системи візуалізації, пілотажно-навігаційних приладів тощо; на вестибулярний апарат впливає система рухливості тренажера. Забезпечення високого рівня інформаційної адекватності тренажера $є$ актуальною та важливою науково-практичною задачею.

На відміну від реального вертольота, час реакції тренажера на керуючі дії пілота залежить не від тривалості фізичних процесів, що запускаються в дію відхиленням важелів керування, а від часу, потрібного на обчислення цієї реакції комп'ютерами тренажера (рис. 1). 

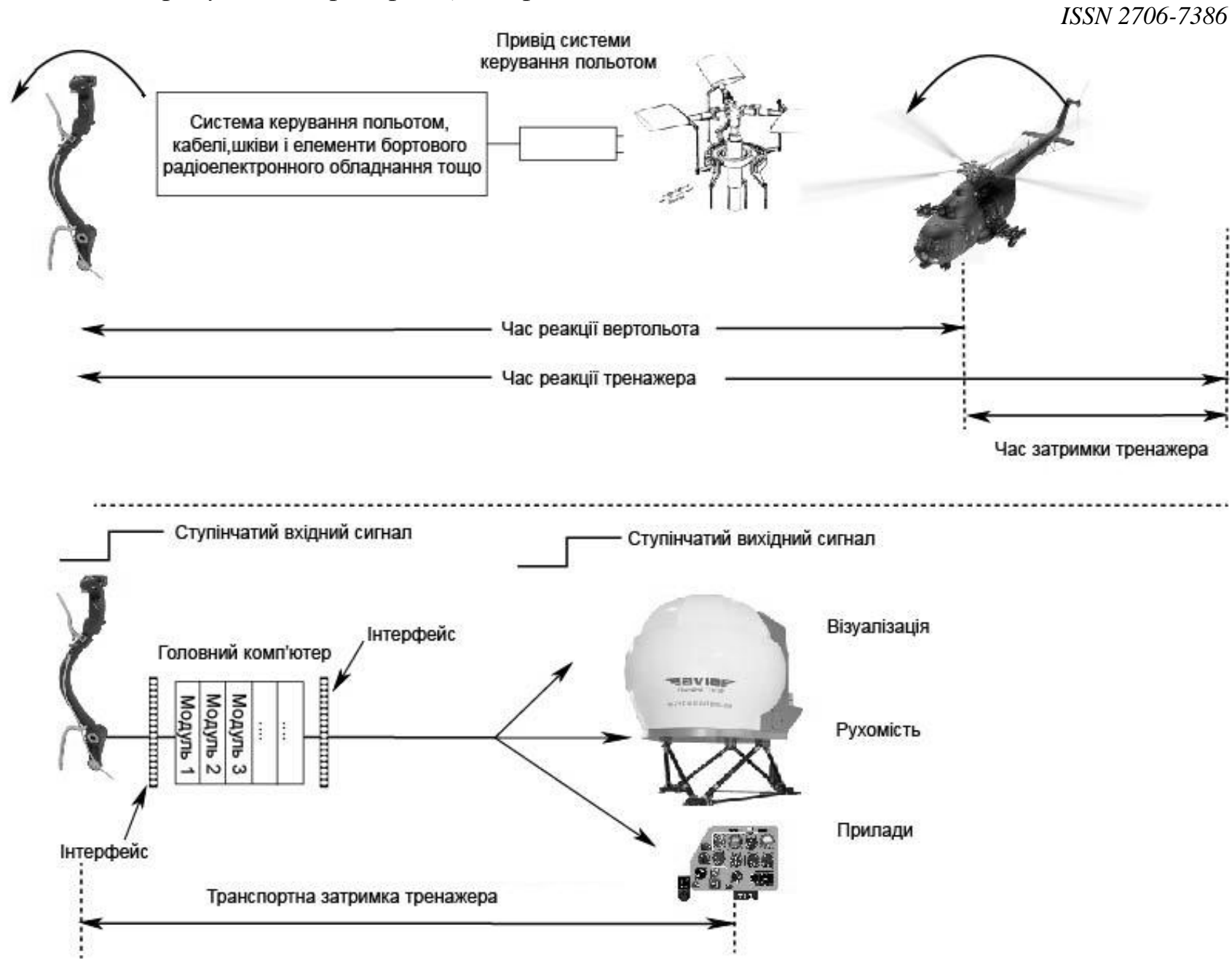

Рис.1. - Час реакції вертольота і тренажера на відхилення важеля керування

Інтервал часу для оброблення сигналів системою керування тренажера, 3 моменту надходження вхідного впливу від важелів керування пілота, до моменту початку реакції системи рухливості, системи візуалізації або приладів називається транспортною затримкою. Отже, це час проходження вхідного сигналу від важеля керування через інтерфейс “обладнання/програмне забезпечення", через кожен з модулів основного комп'ютера та зворотньо через інтерфейс “ програмне забезпечення/обладнання" до системи рухливості, пілотажних приладів і системи візуалізації. До жодного з цих трьох інтервалів часу обробки сигналів не входить динамічна реакція вертольота та (кожен 3 цих трьох інтервалів часу) являє собою транспортну затримку для конкретної системи, яка не залежить від затримки, характерної для модельованого вертольота [2].

Для забезпечення можливості отримання, підготовленим екіпажем, відповідних офіційних документів про рівень професійної підготовки, тренажер повинен бути сертифікований за національними та світовими вимогами, тобто, має бути гарантована адекватність його пілотажних якостей відповідним якостям модельованого вертольота. Для цього тренажер має пройти систему тестів, які визначені “Керівництвом 3 критеріїв кваліфікаційного оцінювання тренажерних пристроїв імітації польоту " [2]. Цим документом встановлюється критерій адекватності для транспортної затримки. У залежності від рівня адекватності тренажера транспортна затримка не повинна перевищувати $85-120$ мс.

У [2] також запропонований метод визначення транспортної затримки. Випробування 3 визначення транспортної затримки проводяться не для порівняння ії з затримками на вертольоті, а для демонстрації прийнятності модельованих характеристик при першочерговому кваліфікаційному оцінюванню. Далі отримані результати використовуються під час кожної періодичної оцінки для підтвердження того, що архітектура програмного забезпечення тренажера не погіршилась. Транспортну затримку 
необхідно вимірювати від входу керуючого сигналу через інтерфейс, через кожен модуль головного комп'ютера тренажера та навпаки через інтерфейс на системи рухливості, приладового обладнання та візуалізації. Потрібно вимірювати тільки максимальне збільшення часу, доданого різними інтерфейсами і обчислювальними елементами тренажера які відсутні на вертольоті. Для цього сигнал оброблюється при проходженні по всій системі від вхідного сигналу важеля керування, на перший інтерфейс, через кожний наступний обчислювальний елемент або інтерфейс і назад - до фізичного зворотнього впливу на пілота через системи рухливості, візуалізації або відображення інформації з приладів у кабіні пілота. При цьому необхідно, щоб моделювання проводилося в нормальному режимі з усіма задіяними елементами програмного забезпечення. Що дозволить забезпечити можливість повторити випробування у кваліфікаційних перевірках у подальшому для підтвердження того, що оновлення програмного забезпечення не вплинуло на “ загальну довжину шляху” проходження сигналу. Потрібно уявляти повний і докладний опис обраного методу та “шляху” сигналу, а також вхідного сигналу та точок реєстрації.

Створений науково-виробничим об’єднанням “АВIA”, м. Кременчук, комплексний пілотажний тренажер (FSTD) вертольота Мi-171 типу V (за класифікацією [2]), чи рівня FFS(D) (за класифікацією [3]) для автоматизації проходження валідаційних випробувань оснащений програмним комплексом TSFlightChart, який дозволяє виконувати обробку польотної інформації відповідно завдань кожного тесту окремо та генерувати формалізований звіт за результатом проходження тесту. Так, кореляційний аналіз польотних параметрів доводить статистично достовірну оцінку транспортної затримки для тих параметрів, для записування яких встановлено відповідні датчики. Однак, для системи візуалізації транспортна затримка визначається [2] як "час між моментом відхилення пілотом важеля управління та першою помітною візуальною зміною зображення". Звичайно, можна було б організувати процес її вимірювання шляхом використання послуг протоколу обміну даними через локальну обчислювальну мережу тренажера, однак, оскільки комплексом TSFlightChart об'єктивно візуальні зміни позакабінної обстановки не фіксуються, то фахівці HBO "ABIA" розробили альтернативний метод вимірювання транспортної затримки для системи візуалізації оптично-електронними засобами, які є незалежними від апаратного та програмного забезпечення тренажера.

Ідея методу полягає у безпосередньому вимірюванні часу між двома подіями у реальному тривимірному просторі. Для цього використовуються два лазерних вказівники, дві швидкодіючі відеокамери та електронний годинник 3 двома рознесеними в просторі індикаторами, які показують абсолютно однаковий час (у форматі номера кадру на відеозаписі).

Перша подія - візуальна фіксація початку руху важеля керування. Друга подія візуальна фіксація початку зміни зображення зовнішнього простору у відповідь на рух пілота важелем керування. У місцях, де відбуваються вказані події, обираються системи координат, жорстко пов'язані, відповідно, з кабіною тренажера і системою рухливості. Для точнішого візуального визначення моментів настання подій можна використати координатні сітки, на які будуть проектуватися відповідні лазерні мітки (рис. 2.а.).

Ручне тестування виконується за наступною методикою.

1. На важелях керування та виконавчих пристроях тренажера жорстко фіксуються лазерні вказівники, мітки яких проектуються на базові площини відліку таким чином, що в початковому стані тренажера перед початком вимірювання лазерні мітки по всіх каналах знаходяться в відповідних початках координат.

2. Навпроти початків систем координат жорстко фіксуються центри об'єктивів відеокамер.

3. Виконується ступінчасте відхилення відповідного важеля керування. Обидві відеокамери при цьому фіксують переміщення відповідних лазерних міток та показання 
індикаторів часу (номери кадрів). Вимірювання проводяться у нормальному режимі роботи локальної обчислювальної мережі з усіма задіяними елементами програмного забезпечення.

4. Під час перегляду кожного кадру отриманих відеозаписів фіксуються ті номери, які відповідають настанню першої та другої подій. Різниця показів індикаторів часу в моменти початку руху лазерних міток (у форматі часу) і $є$ транспортною затримкою.

На рисунку 2 зображені результати тестування. Були використані відеокамери зі швидкодією 240 кадрів/с. Тобто, роздільна здатність записів становила 4 мс.

Кадри з номерами 6549 (рис. 2.a, 2.б) є вихідними для відліку транспортної затримки. У кадрі 6550 (рис. 2.в) вперше візуально зафіксовано переміщення ручки управління. У кадрі 6564 (рис. 2.г) вперше візуально зафіксована зміна у переміщенні зображення системи візуалізації. Міжкадровий інтервал становить $1 / 120$ с. Транспортна затримка дорівнює: $(6564-6550) \times$ $1 / 120=0,117 \mathrm{c}=117 \mathrm{Mc}$.
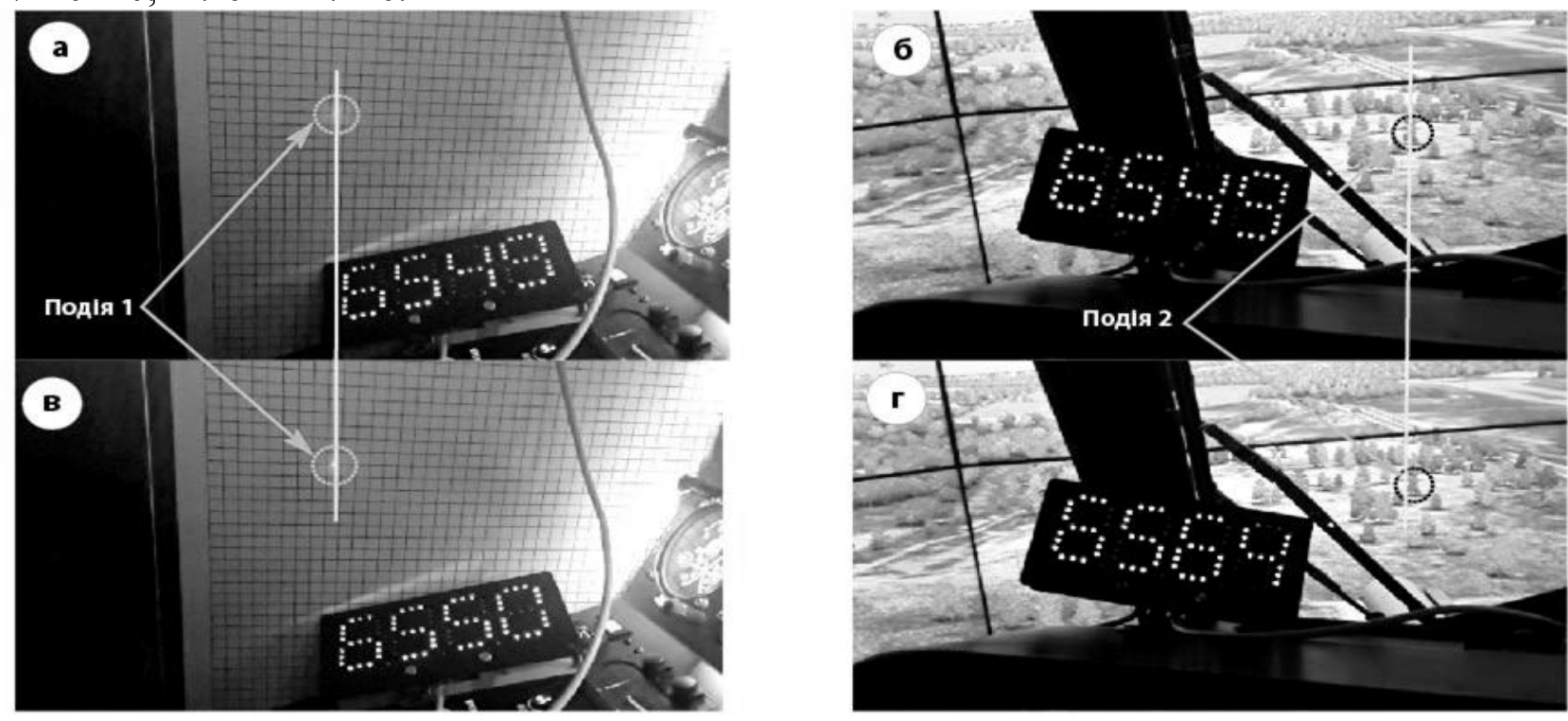

\section{Висновки}

Рис. 2. Зображення результатів тестування

Таким чином, пропонується простий, прозорий та універсальний (лазерні вказівники та відеокамери на тренажері можна розмістити, практично, де завгодно) метод вимірювання транспортних затримок у системі керування тренажера, який не залежить від системного i прикладного програмного забезпечення, а також апаратного забезпечення локальної обчислювальної мережі тренажера.

\section{СПИСОК ЛІТЕРАТУРИ}

1. Определение и классификация ошибок пилота [Електронний ресурс] - Режим доступу: :http://avia.pro/blog/opredelenie-i-klassifikaciya-oshibok-pilota.

2. Doc 9625. Руководство по критериям квалификационной оценки тренажерных устройств имитации полета Том II. Вертолеты. Номер заказа: 9625-2 ISBN 978-92-9249-6234. С ИКАО, 2014.

3. Certification Specification for Helicopter Simulation Training Devices (CS-FSTD(H)). Initial issue, 26 June 2012, European Aviation Safety Agency. 


\section{Андріснко Олександр Віталійович}

кандидат психологічних наук, старший науковий співробітник Державного науково-дослідного інституту випробувань і сертифікації озброєння та військової техніки, м. Чернігів, Україна

https://orcid.org/0000-0001-8450-801X

E-mail: Flater2009@ukr.net

\section{Гученко Микола Іванович}

доктор технічних наук, професор, старший науковий співробітник наукововиробничого об'єднання “АВIA", м. Кременчук, Україна https://orcid.org/0000-0001-8450-8011

\section{Зінченко Володимир Павлович}

кандидат технічних наук, старший науковий співробітник наукововиробничого об'єднання “АВIA”, м. Кременчук, Україна https://orcid.org/0000-0001-8450-8012

\section{Тупіков Костянтин Сергійович}

інженер-електронік науково-виробничого об'єднання “АВIA”, м. Кременчук, Україна https://orcid.org/0000-0001-8450-8013

\section{Кушпіль Андрій Ананатолійович} інженер-програміст науково-виробничого об'єднання “АBIA”, м. Кременчук, Україна https://orcid.org/0000-0001-8450-8014

\section{Andrienko Oleksandr}

Candidate of Psychological Sciences, Senior Researcher of State Scientific Research Institute of Armament and Military Equipment Testing and Certification, Chernihiv, Ukraine https://orcid.org/0000-0001-8450-801X

E-mail: Flater2009@ukr.net

\section{Huchenko Mykola}

Doctor of Technical Science, Professor, Senior Researcher, Scientific and production association "AVIA", Ltd., Kremenchuk, Ukraine https://orcid.org/0000-0001-8450-8011

\section{Zinchenko Volodymyr}

Candidate of Technical Science, Senior Researcher, Scientific and production association "AVIA", Ltd., Kremenchuk, Ukraine https://orcid.org/0000-0001-8450-8012 Tupikov Costiy

Electronic engineer, Scientific and production association "AVIA", Ltd., Kremenchuk, Ukraine https://orcid.org/0000-0001-8450-8013

\section{Cushpil Andriy}

software engineer, Scientific and production association "AVIA", Ltd., Kremenchuk, Ukraine https://orcid.org/0000-0001-8450-8014

\section{OPTOELECTRONIC METHOD OF DETERMINING THE TRANSPORT DELAY IN THE CONTROL SYSTEM OF THE SIMULATOR}

O. Andrienko, M. Huchenko, V. Zinchenko, C. Tupikov, A. Cushpil

The article proposes a method of determining the transport delay in the simulator control system using a universal device. The essence of the method is to measure the time directly between two events in real threedimensional space. The test instruments include two laser pointers, two high-speed camcorders and an electronic clock with two space-separated indicators that show exactly the same time (in the format of frame number in the video recording). The first event is a visual fixation of the control lever movement start. The second event is a visual fixation of the beginning of the change in the image of the outer space in response to the movement of the control lever induced by a pilot. In places where these events occur, coordinate systems are selected that are rigidly connected, respectively, to the simulator cabin and mobility system. For more accurate visual determination of the occurrence of events, it is possible to use coordinate grids on which the corresponding laser marks will be projected.

NVO "AVIA" (Kremenchuk) has created an integrated flight simulator (FSTD) of Mi-171 helicopter type V FFS $(D)$ equipped with TSFlightChart software for automatization of the validation tests, which allows to perform flight information processing according to the tasks of each test separately and generate a formalized report on the results of the test.

A simple, transparent and versatile (laser pointers and camcorders on the simulator can be placed, virtually anywhere) method of measuring transport delays in the simulator control system is proposed, which is independent from system and applied software, as well as from hardware of the simulator's local area network.

Keywords: flight simulator, validation tests, transport delay. 